\title{
CFD MODELING OF SLURRY PIPELINE AT DIFFERENT PRANDTL NUMBERS
}

\author{
Om Parkash ${ }^{1,2^{*}}$, Arvind Kumar ${ }^{2}$, Basant Singh Sikarwar ${ }^{3}$
}

\begin{abstract}
The present work shows the slurry flow characteristics of glass beads having density $2470 \mathrm{~kg} / \mathrm{m}^{3}$ at different Prandtl number through a horizontal pipeline. The simulation is conducted by Eulerian two-phase model using RNG $k-\varepsilon$ turbulence closure in available commercial software ANSYS FLUENT. The transportation of solid particulates has the settling behaviour in the slurry pipeline and that leads to the sedimentation and blockage of the pipeline resulting more power and pressure drop in the pipeline. Therefore, it is important to know the transport capability of the solid particulates at different Prandtl fluids to minimise the pressure loss. The fluid properties at four Prandtl numbers i.e. 1.34, 2.14, 3.42 and 5.83 is used to carry the solid concentration ranges from 30-50\% (by volume) at mean flow-velocity ranging from 3 to $5 \mathrm{~ms}^{-1}$. The obtained computational results are validated with the published data in the literature. The results show that the pressure-drop rises with escalation in flow velocity and solid concentration at all Prandtl number. It is found that the suspension stability enhancement is considerable for lower range of Prandtl number and decreases for higher range of Prandtl number. Finally, glass beads concentration contours, velocity contours, concentration profile, velocity profiles and pressure drop are predicted to understand the slurry flow for chosen Prandtl numbers.
\end{abstract}

\section{Keywords: 3D Horizontal Pipeline, Prandtl Number, Pressure Drop, Particulates Concentration, Velocity Distribution}

\section{INTRODUCTION}

Conveyance of solid particulates through pipelines and pumps is the most common phenomenon used by various industries such as mining, chemical, cement, iron ore industries and especially in power plants across the world. This mode of slurry transportation through pipeline systems facilitate various advantages such as incessant conveyance, low traffic, less air pollution, negligible ecological disorder, long distance conveyance competency etc. Most of the research reported the experimental studies to know pressure drop, concentration distribution and velocity distribution in the slurry pipeline. O'Brien [1] and Rouse [2] displayed the concentration dispersal for low volume fraction of solids in an open channel using diffusion model. Ismail [3] further improved the diffusion model by relating shear velocity gradient with mass transfer coefficient. The work on flow of suspension through pipeline include the work of Shook et al. [4]-[5] and Karabelas [6]. Turian et al. [7] experimented the effect of Reynolds number and particulate-concentration on friction loss for minute glass beads particle slurry. Further the effect of particulate size in slurry flow and the heterogeneous distribution of coal ash slurry investigated by Roco \& Shook [8]-[9]. Colwell et al. [10] carried out an experiment for slurry mixture consisting of sand and polystyrene particles in a horizontal $0.050 \mathrm{~m}$ diameter pipeline. Velocity and concentration profiles were depicted at three different positions and optimal entry lengths were estimated for the chosen particle slurry.

Some of the preeminent researches include the work of many researchers who focused mainly on dispersal of solid particulates Gillies et al. [11] - [13]. Matousek [14] performed the laboratory experiment by using sand water mixture flow in a $0.105 \mathrm{~m}$ diameter pipe and analyzed the flow characteristic at three different inclinations i.e. horizontal, vertical and $-35^{\circ}$ descendent pipes and observed the flow pattern variation for fully stratified and suspended flow. Further, most of the research reported the experimental and numerical studies to know pressure drop, velocity distribution and concentration distribution in the slurry pipeline. Ling et al. [15] numerically investigated the sand-water mixture flow in a horizontal pipe using algebraic slip model (ASM). This paper was recommended for publication in revised form by Regional Editor Siamak Hoseinzadeh 1Department of Mechanical Engineering, Amity University Haryana, Gurgaon, India 2Department of Mechanical Engineering, JC Bose University of Science and Technology, YMCA, Faridabad, India 3Department of Mechanical Engineering, Amity University Uttar Pradesh, Noida, India ${ }^{*}$ E-mail address: om.mech8@gmail.com Orcid id: 0000-0001-7080-570X, 0000-0003-0495-199X, 0000-0001-8532-7528 Manuscript Received 28 April 2019, Accepted 26 July 2019 
The findings show motivating results for mean slurry velocity, which has been found greater than the settling velocity of the solid particulates. Krampa-Morlu et al. [16] investigated slurry flow parameters for coarser particles in a vertical pipe using k- $\varepsilon$ turbulence closure and studied the particle-size effect and concentration effect on flow characteristics. Kaushal et al. [17] analyzed particle-size (440 $\mu \mathrm{m}$ and $125 \mu \mathrm{m}$ ) effect on pressuredrop for highly concentrated slurry flow in a horizontal pipe of $0.0549 \mathrm{~m}$ diameter. Kaushal et al. [18] experimented near wall lifts for coarser solid particulates in a slurry pipeline of $0.0549 \mathrm{~m}$ diameter and reported the effect of slip velocity on pressure drop. Lin and Ebadian [19] used algebraic slip model and analyzed various developing parameters of sand water mixture at entry section of the pipeline. Lahiri and Ghanta [20] proposed a theoretical model by using support vector regression (SVR) and genetic algorithm (GA) to predict the pressure drop in a solid-liquid mixture flow. Kumar et al. [21] performed an experiment on bend pressure drop of slurry pipeline using multi-tube U-tube manometer assembly and resulted experimental data was compared with 3D CFD modeling simulation pressure drop data and concluded that pressure-drop at the outside wall is more than the inside wall of the bend. Chandel et al. [22] studied the pressure drops and rheological features of the fly-ash slurry pipeline and illustrated settling behavior of slurry for various flow velocities for slight dip in pressure drop by adding an additive. Monteiro and Bansal [23] discussed the variation of pressure drop with ice concentration, pipe diameters and slurry velocity using theoretical rheological model predicting behavior of slurry flow parameters in the pipe. Naik et al. [24] studied the rheological characteristics at different temperature using cationic surfactant and counter ion, which reduces surface tension, enhances suspension stability of solid particulates. Kaushal et al. [25]-[26] carried out the CFD modeling for fine particles and mono dispersal particles at higher concentration through horizontal pipelines by using Eulerian two-phase model and illustrated pressure drop characteristics along with other flow constraints. Gopaliya and Kaushal [27] studied the grain size effect on slurry flow characteristics using CFD. Melorie et al. [28] found the addition of hydrated lime increases the rheological behavior and high yield stress for all volumetric concentration of slurry. Assefa et al. [29] proposed new empirical viscosity model for the highly concentrated Bingham slurry ranging from 50 $70 \%$ by weight and found the proposed viscosity model in agreement with the experimental study for determining the viscosity of multi sized particulates Bingham slurry flowing at higher concentration. Singh et al. [30] added an additive sodium bicarbonate in highly concentrated fly ash slurry, which modified the rheological characteristics of the fly ash slurry. Singh et al. [31] further added bottom ash to the fly ash in the solid concentration ranging from $10-30 \%$ by weight and observed that adding coarser bottom ash results in improved rheological characteristics and suspension stability. Parkash et al. [32] reported the simulation of 440 $\mu \mathrm{m}$ solid particulates size slurry in the range of 10 to $30 \%$ (by volume) at Prandtl number, $\operatorname{Pr}-5.83$. Hoseinzadeh et al. [33]-[38] reported the heat transfer characteristics through porous fins with multiple phase change material and presented the exergy energy analysis of power plant. The effect of MHD nanofluid heat transfer in a baffled U shaped enclosure is studied by Ma et al. [39] -[41]. Mansoury et al. [42] studied the effect of A12O3/water nanofluid on parallel flow heat exchanger. Bhatti et al. [43] developed a mathematical model of MHD nanofluid that accounts the effect of thermal radiation and chemical reaction. Sheikholeslami et al. [44]-[54] studied heat transfer characteristics effect of nanofluid through fins and heat exchanger. Several other studies [55]-[69] examined the effect of thermal performance through mini channels, microprocessors, staggered and pin fin heat sink using nanofluid. The current work on computational modeling can be further enhanced in finding the temperature profile and other parameters through various thermodynamic models [7079]. Therefore, many researchers developed different solutions for the slurry flow using limited experimental data. In fact, most of the designers rely and depend on the data generated from pilot plant test facility for designing slurry transport systems. Thus, the work on slurry pipeline design is still limited and offers numerous opportunities particularly in case of higher concentration slurries. Additionally, setting up a new slurry pipeline system is a tedious and costly affair and needs to be minimized. Further, it is observed that CFD tools demonstrate capabilities to understand the slurry flow behavior at selected location in the pipeline, which allow the researchers to carry out parametric study within a short period that too at low cost.

In the literature, researchers focused on predicting suspension stability of slurry flow with or without adding an additive. However, there is no literature available for slurry pressure drop using Prandtl number. Thus, a better understanding of solid particulates slurry flow characteristics i.e. pressure drop, settling velocity of solid particulates, solid particulates distribution and velocity distribution at different Prandtl fluids is prerequisite to improve the present slurry pipeline system. The present work demonstrates the characteristics of slurry flow focusing transportation capabilities of solid particulates at different Prandtl fluids that helps the pipe 
designer to understand the slurry flow behavior across the pipeline systems. Computational fluid dynamics possess abundant scope and competence for evaluating aforementioned parameters at different cross-sections of the pipeline. An effort has been done to predict the slurry flow characteristics for $125 \mu \mathrm{m}$ particle size by

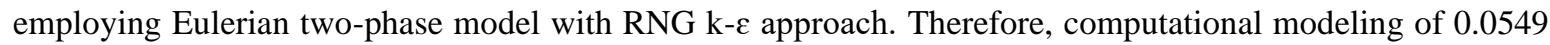
$\mathrm{m}$ diameter pipeline has been carried out for the solid concentration, 30 to $50 \%$ (by volume) in the velocity range of 3 to $5 \mathrm{~ms}^{-1}$ at different Prandtl fluids. The validation of the developed computational model is done with the available published data by Kaushal et al. 2007.

\section{MATHEMATICAL MODEL}

\section{Eulerian Model}

An efficient Eulerian model of granular flow containing liquid and solid phases is used for simulation. The two phases are presumed to be $\alpha_{s}$ and $\alpha_{l}$ for $\alpha_{s}+\alpha_{l}=1$. It solves the governing equations for each phase and the phase coupling is attained by pressure and interphase exchange coefficients. The solid particle in the slurry flow subjected to following forces i.e. Static/solid pressure gradient $\left(\nabla P / \nabla P_{S}\right)$, viscous $\left(\nabla \cdot \overline{\tau_{f}}\right)$ and body forces $(\rho \vec{g})$, Lift/virtual forces and forces due to phase velocities difference $\left(K_{s f}\left(\vec{v}_{s}-\vec{v}_{f}\right)\right)$. The lift and virtual mass coefficient $\left(C_{v m} / \mathrm{C}_{\mathrm{L}}\right)$ assumed as 0.5 in the present study. The slurry is two-phase flow in which micro size particles dissolve in the liquid. The two phase Navier-stokes equation has been solved to knowing the velocity and pressure field in the domain a $0.0549 \mathrm{~m}$ diameter pipe. The governing equations with appropriate boundary conditions and assumptions are [25]:

\section{Governing Equations \\ Continuity Equation}

$$
\nabla .\left(\alpha_{f} \rho_{f} \vec{v}_{f}\right)=0
$$

Here, $f$ can be considered as $l$ for liquid phase and $s$ for solid phase.

\section{Momentum Equations}

For liquid phase:

$$
\left[\begin{array}{l}
\nabla \cdot\left(\alpha_{l} \rho_{l} \vec{v}_{l} \vec{v}_{l}\right)=-\alpha_{l} \nabla P+\nabla \cdot\left(\overline{\overline{\tau_{l}}}+\overline{\overline{\tau_{f, l}}}\right)+\alpha_{l} \rho_{l} \vec{g}+K_{s l}\left(\vec{v}_{s}-\vec{v}_{l}\right)+C_{v m} \alpha_{s} \rho_{l}\left(\vec{v}_{s} \cdot \nabla \vec{v}_{s}-\vec{v}_{l} \cdot \nabla \vec{v}_{l}\right) \\
+C_{L} \alpha_{s} \rho_{l}\left(\vec{v}_{l}-\vec{v}_{s}\right) \times\left(\nabla \times \vec{v}_{l}\right)
\end{array}\right]
$$

For solid phase:

$$
\left[\begin{array}{l}
\nabla \cdot\left(\alpha_{s} \rho_{s} \vec{v}_{s} \vec{v}_{s}\right)=-\alpha_{s} \nabla P-\nabla P_{s}+\nabla \cdot\left(\overline{\overline{\tau_{s}}}+\overline{\overline{\tau_{f, l}}}\right)+\alpha_{s} \rho_{s} \vec{g}+K_{l s}\left(\vec{v}_{l}-\vec{v}_{s}\right)+C_{v m} \alpha_{s} \rho_{l}\left(\vec{v}_{l} \cdot \nabla \vec{v}_{l}-\vec{v}_{s} \cdot \nabla \vec{v}_{s}\right) \\
+C_{L} \alpha_{s} \rho_{l}\left(\vec{v}_{s}-\vec{v}_{l}\right) \times\left(\nabla \times \vec{v}_{l}\right)
\end{array}\right]
$$

Here $\overline{\tau_{f, l}}$ is the Reynolds stress tensor, whereas $\overline{\tau_{s}}$ and $\overline{\tau_{l}}$ are the viscous stress tensors for solid and liquid phase respectively and are given by:

$$
\overline{\tau_{s}}=\left[\alpha_{s} \mu_{s}\left(\nabla \vec{v}_{s}+\nabla \vec{v}_{s}^{f r}\right)+\alpha_{s}\left(\lambda_{s}-\frac{2}{3} \mu_{s}\right) \nabla \cdot \vec{v}_{s} \bar{I}\right]
$$

and

$$
\overline{\tau_{l}}=\left[\alpha_{l} \mu_{l}\left(\nabla \vec{v}_{l}+\nabla \vec{v}_{l}^{f r}\right)\right]
$$

Here superscript ' $f r$ ' above the velocity vector represents the transpose and $\overline{\bar{I}}$ represents the identity tensor and $\lambda_{s}$ indicates the bulk viscosity of the solid as given below: 


$$
\lambda_{s}=\left[\frac{4}{3} \alpha_{s} \rho_{s} d_{s} g_{o, s S}\left(1+e_{S S}\right)\left(\frac{\Theta_{s}}{\pi}\right)^{\frac{1}{2}}\right]
$$

$\mathrm{d}_{\mathrm{s}}$ represents the spherical particle diameter which is taken as $125 \mu \mathrm{m}$ in the present study and $g_{o, s s}$ is the radial distribution function which is defined as;

$$
g_{o, s s}=\left[1-\left(\frac{\alpha_{s}}{\alpha_{s, \max }}\right)^{\frac{1}{3}}\right]^{-1}
$$

Here, $\alpha_{s, \max }$ is the static settled concentration, $\Theta_{s}$ is the granular temperature, $e_{s s}$ is the restitution coefficient and $\mu_{l}$ is the shear viscosity of liquid.

$\mu_{s}$ the shear viscosity of solid defined as:

$$
\mu_{s}=\mu_{s, c o l}+\mu_{s, k i n}+\mu_{s, l r}
$$

Here $\mu_{s, c o l}, \mu_{s, k i n}$ and $\mu_{s, l r}$ are collisional, kinetic and frictional viscosities respectively. These can be defined as:

$$
\begin{gathered}
\mu_{s, c o l}=\frac{4}{5} \alpha_{s} \rho_{s} d_{s} g_{o, s s}\left(1+e_{s s}\right)\left(\frac{\Theta_{s}}{\pi}\right)^{\frac{1}{2}} \\
\mu_{s, l r}=\frac{P_{s} \sin \varphi}{2 \sqrt{I_{2 D}}} \\
\mu_{s, k i n}=\left[\frac{\alpha_{s} d_{s} \rho_{s} \sqrt{\Theta_{s} \pi}}{6\left(3-e_{s s}\right)}\left[1+0.4\left(1+e_{s s}\right)\left(3 \mathrm{e}_{s s}-1\right) \alpha_{s} g_{o, s s}\right]\right]
\end{gathered}
$$

$I_{2 D}$ is another invariant of the deviatory strain rate tensor defined for solid phase, $\varphi$ is the internal friction angle considered $30^{\circ}$ in the present calculations and $P_{s}$ indicates the solid pressure as given below:

$$
P_{s}=\left[\alpha_{s} \rho_{s} \Theta_{s}+2 \rho_{s}\left(1+e_{s S}\right) \alpha_{s}^{2} g_{o, s S} \Theta_{S}\right]
$$

$K_{s l}$ represents the inter-phase momentum exchange coefficient defined as:

$$
K_{s l}=K_{l s}=\frac{3}{4} \frac{\alpha_{s} \alpha_{l} \rho_{l}}{V_{r, s}^{2} d_{s}} C_{D}\left(\frac{R e_{s}}{V_{r, s}}\right)\left|\vec{v}_{s}-\vec{v}_{l}\right|
$$

$C_{D}$ represents the drag coefficient defined by:

$$
C_{D}=\left(0.63+4.8\left(\frac{R e_{s}}{V_{r, s}}\right)^{\frac{-1}{2}}\right)^{2}
$$

$R e_{f}$ is the relative Reynolds number for the liquid and solid phase and defined as:

$$
R e_{f}=\frac{\rho_{l} d_{s}\left|\vec{v}_{S}-\vec{v}_{l}\right|}{\mu_{l}}
$$

$V_{r, s}$ represents the terminal velocity of the solid phase. 
Mixture Viscosity

$$
\mu_{m}=\mu_{l}(1+2.5 \phi)
$$

Where $\mu_{m}$ represents the viscosity of the mixture, $\mu_{l}$ is liquid viscosity in slurry mixture and $\phi$ is the volume fraction given by $\left(\phi=\frac{C_{v f}}{100}\right)$;

\section{Mixture Density}

$$
\rho_{m}=\frac{C_{v f}\left(\rho_{s}-\rho_{l}\right)}{100}+\rho_{l}
$$

Where $\rho_{m}$ represents the density of slurry mixture, $C_{v f}$ is the concentration of solid by volume, $\rho_{s}$ represents the solid density and $\rho_{l}$ represents the liquid density.

\section{Prandtl Number}

$$
\operatorname{Pr}=\frac{\mu_{m} C_{p}}{K}
$$

where Pr represents the Prandtl number, $\mu_{m}$ is the liquid viscosity, $\mathrm{C}_{\mathrm{p}}$ is the specific heat of liquid and $\mathrm{K}$ denotes the thermal conductivity of liquid.

The coupling of pressure-velocity with Euler two-phase model is achieved by Semi Implicit Pressure Linked Equation algorithm. Standard wall functions comprising semi-empirical formula and functions is assumed for

\begin{tabular}{|c|c|c|c|c|}
\hline \multicolumn{5}{|c|}{ Liquid phase } \\
\hline $\begin{array}{c}\text { Prandtl number } \\
\text { (Pr) }\end{array}$ & Density $\left(\mathrm{kg} / \mathrm{m}^{3}\right)$ & $\begin{array}{l}\text { Viscosity } \\
\text { (kg/m-sec) }\end{array}$ & $\begin{array}{c}\text { Specific heat } \\
\text { (KJ/Kg-K) }\end{array}$ & $\begin{array}{c}\text { Thermal Conductivity } \\
\qquad(\mathrm{W} / \mathbf{m K})\end{array}$ \\
\hline 1.34 & 937 & 0.000217 & 4.256 & 0.688 \\
\hline 2.14 & 973 & 0.000343 & 4.199 & 0.671 \\
\hline 3.42 & 987 & 0.000528 & 4.182 & 0.645 \\
\hline 5.83 & 997 & 0.000855 & 4.179 & 0.613 \\
\hline
\end{tabular}
simulations. The properties of the liquid phase at different Prandtl number is defined in the Table 1.

Table 1. Properties of liquid phase 


\section{Flow Chart}

The flow chart of the simulation process consist of the following steps as shown below:

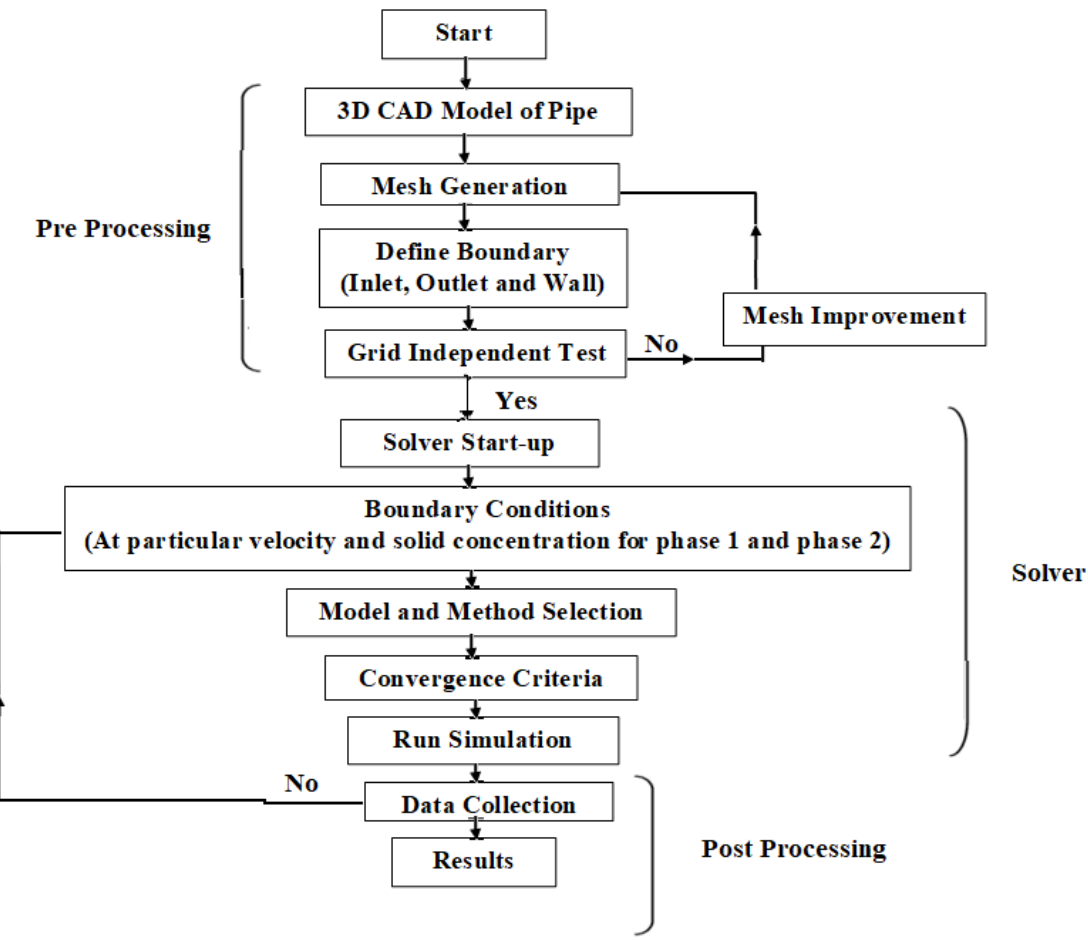

\section{COMPUTATIONAL MODELING}

\section{Computational Domain and Grid Independent Test}

The computational grids for $3.8 \mathrm{~m}$ long and $0.0549 \mathrm{~m}$ diameter horizontal pipe is generated in ANSYS 16.0. The pipe geometry having $462 \mathrm{~K}$ hexahedral and quad elements is finalized conducting suitable grid independent test. The grid independent test is performed with $154 \mathrm{~K}, 243 \mathrm{~K}, 382 \mathrm{~K}, 462 \mathrm{~K}$ and $522 \mathrm{~K}$ hexahedral and quad elements at $C_{v f}=40 \%$ and $V_{m}=5 \mathrm{~ms}^{-1}$. The solid phase velocity profile w.r.t. radial distance at the outlet section of the pipe is shown in the Figure 1 (b). It is found that the geometry containing $462 \mathrm{~K}$ and $522 \mathrm{~K}$ cells show the identical results. Hence, a grid with $462 \mathrm{~K}$ cells is preferred for the simulation as shown in the Figure 1 (a). The minimum orthogonal quality and maximum ortho skewness representing the mesh quality are 0.93 and 0.065 respectively. The CPU with configuration i5 processing unit and 8 GB RAM is used and utilized the average time of four hours for converging the solution at particular velocity and solid concentration for the selected mesh model. The pipe length is chosen more than 50D in order to satisfying the criteria of fully developed flow.

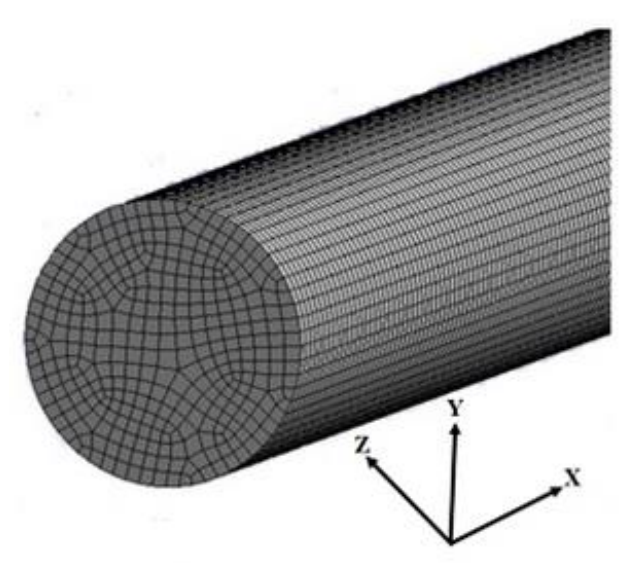

a)

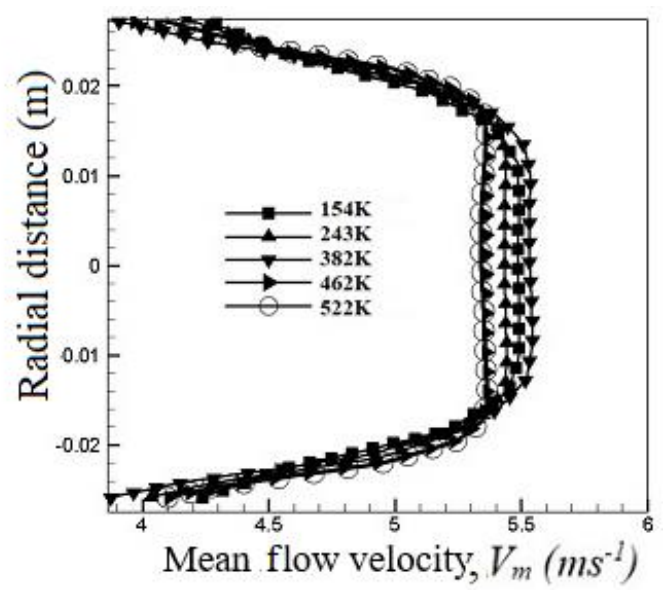

b)

Figure 1. a) Mesh in computational domain and b) velocity profile at $V_{m}=5 \mathrm{~ms}^{-1}$ and $C_{v f}=40 \%$ 


\section{Boundary Conditions}

The computational pipe domain comprises of three faces named as inlet, outlet and wall boundaries to conduct the simulation. The boundary conditions at inlet and outlet section of the pipeline is applied at definite velocity and volume fraction. The wall boundary is considered with no slip condition and roughness constant is assumed as 0.5 .

$C_{v f}$ represents the efflux concentration defined as:

$$
C_{v f}=\frac{1}{A} \int_{A} \bar{\alpha}_{S} d A \cong \frac{1}{A} \int_{A} \alpha_{S} d A
$$

\section{Solution Methods and Convergence Criteria}

A second order upwind scheme is considered to simplify the turbulence kinetic energy, volume fraction, momentum and turbulence dissipation rate. This arrangement offers high precision, fidelity and converging of the solutions. The converging condition works on the basis of residual value of various constraints viz. mass, turbulent kinetic, velocity, dissipation energy and volume fractions. The values are pre-set to 0.001 time the initial residual values for every constraint.

\section{COMPUTATIONAL RESULTS}

The work shows the computed pressure drops in the last a meter length of the pipeline, whereas results for glass beads velocity and concentration are projected at the outlet section of the pipeline.

\section{Solid Concentration Contours}

Figure 2 depicts the solid concentration contours at the outlet section of the pipeline for different Prandtl numbers $(\operatorname{Pr}=1.34-5.83)$ at the mean flow velocity, $V_{m}=3 \mathrm{~ms}^{-1}$ and solid concentration range, $C_{v f}=$ $30-50 \%$ (by volume). It has been found that the sedimentation of the solid particulates occur at the bottom of the pipeline for all Prandtl numbers as depicted in the Figure 2(a) at $C_{v f}=30 \%$. At low Prandtl number $(\operatorname{Pr}=$ $1.34,2.14$ and 3.42) solid particulates show greater dispersal across the pipe wall than the dispersal rate at higher Prandtl number as depicted in the Figure 2 (a) at $\operatorname{Pr}=5.83$. The settling of solids is varying because of the change in viscosity of the slurry mixture for different Prandtl numbers. The transportation of solid particulates in slurry pipeline also intensifies with increase in solid concentration as it increases the momentum exchange between the solid particulates that enriches the solid-solid and solid wall interaction in the slurry pipeline as depicted in the Figure 2(b) and 2(c). Similar effects can also be perceived for higher mean flow velocity and solid concentration for different Prandtl numbers as depicted in the Figures 3(a-c) and 4(a-c).

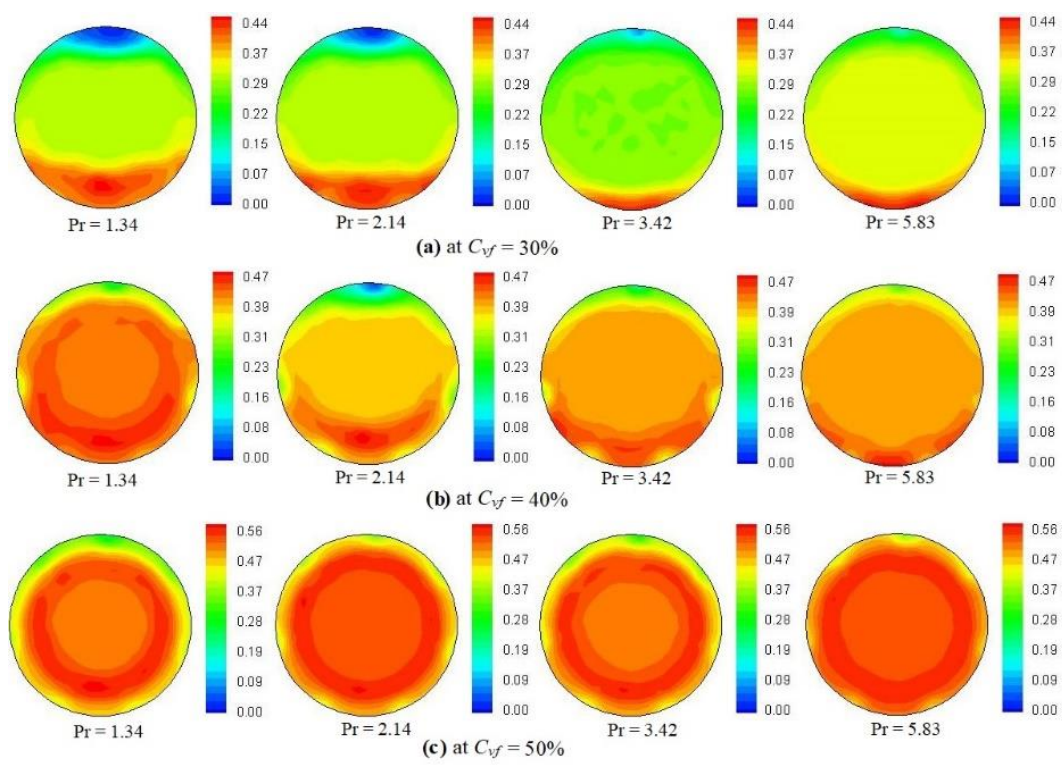

Figure 2. Particulates concentration contour at $V_{m}=3 \mathrm{~ms}^{-1}$ for different Prandtl number at a) $C_{v f}=30 \%$, b) $C_{v f}=40 \%$, and c) $C_{v f}=50 \%$ 


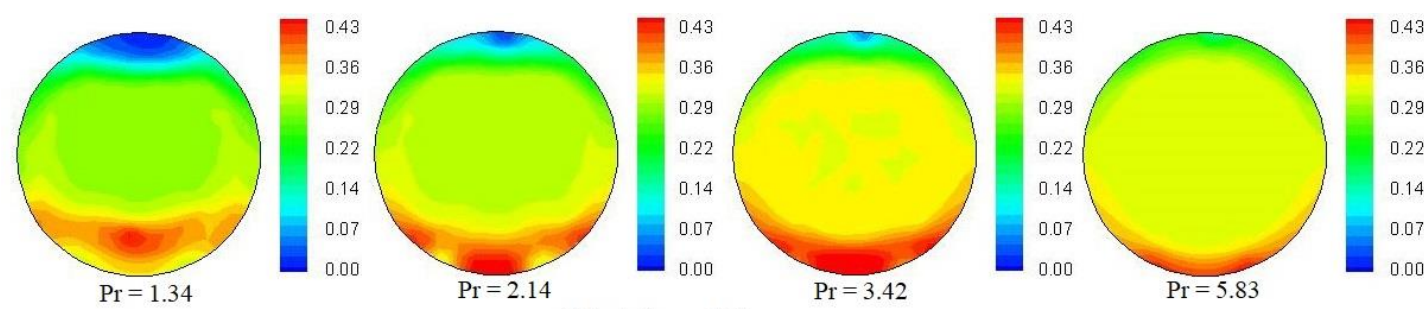

at $C_{v f}=30 \%$
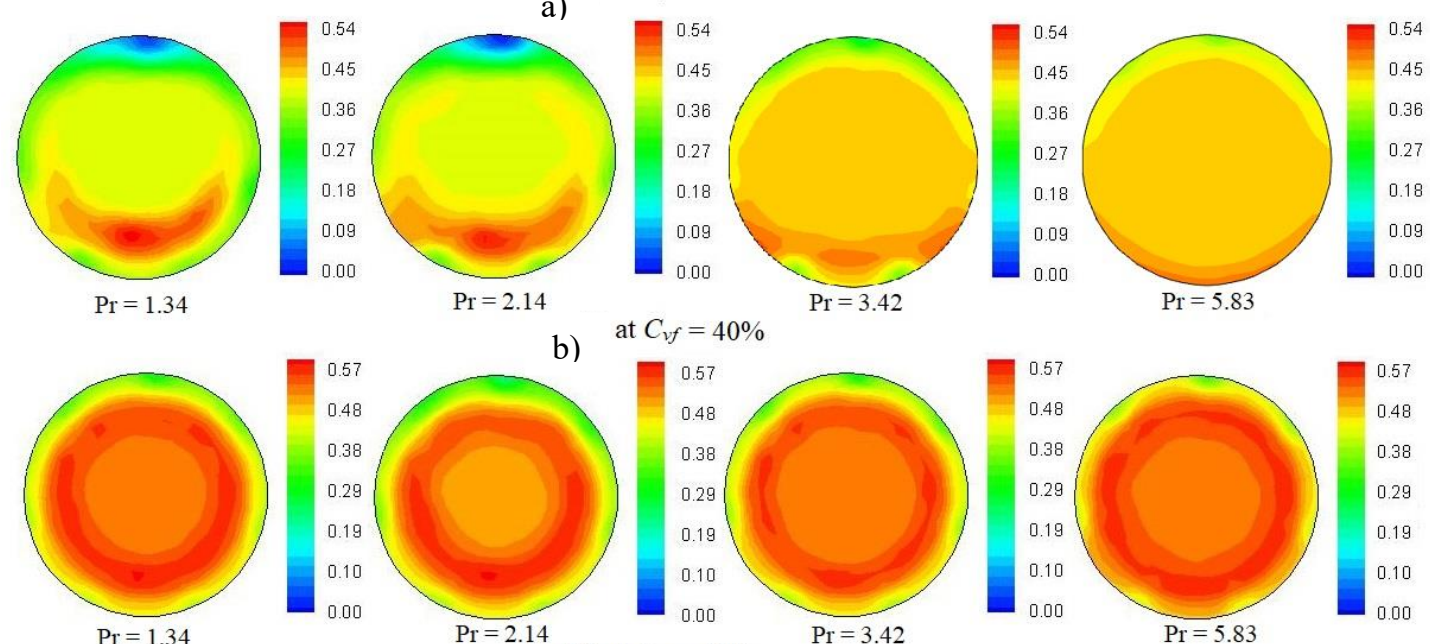

b)
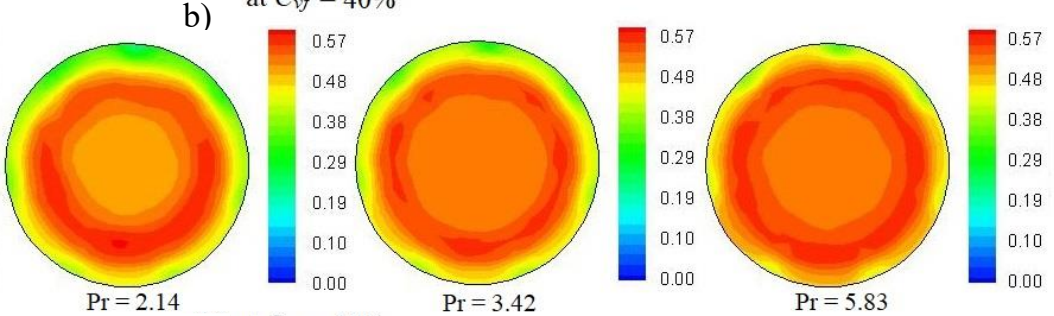

c)

Figure 3. Particulates concentration contour at $V_{m}=4 \mathrm{~ms}^{-1}$ for different Prandtl number at a) $C_{v f}=30 \%$, b) $C_{v f}=40 \%$, and c) $C_{v f}=50 \%$
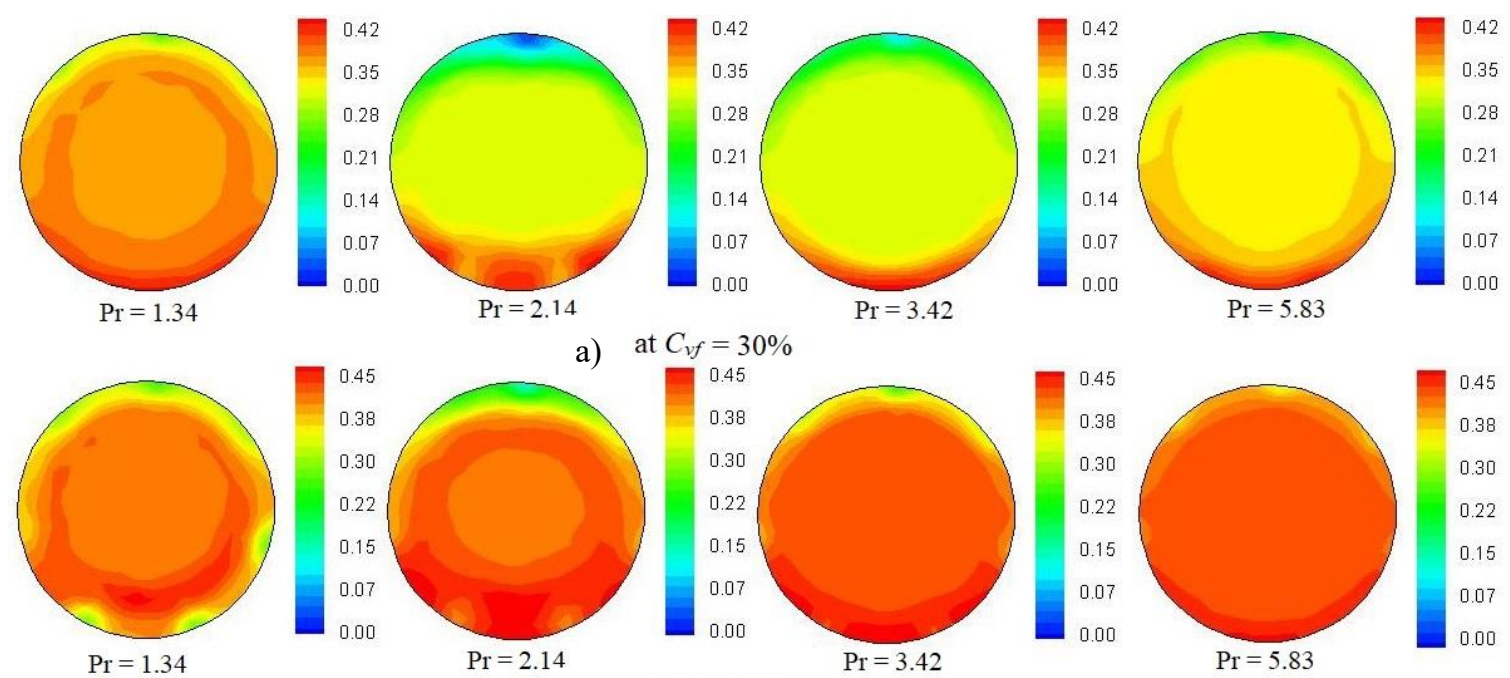

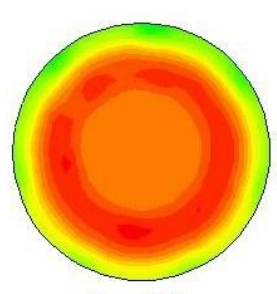

$\operatorname{Pr}=1.34$

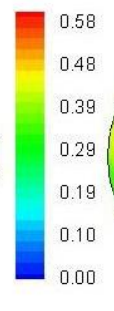

b)

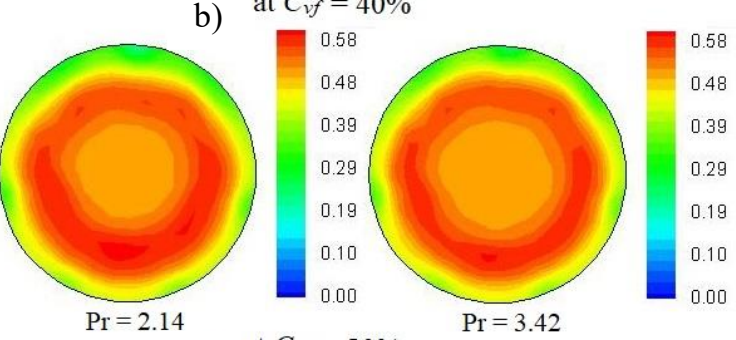

c) at $C_{v f}=50 \%$

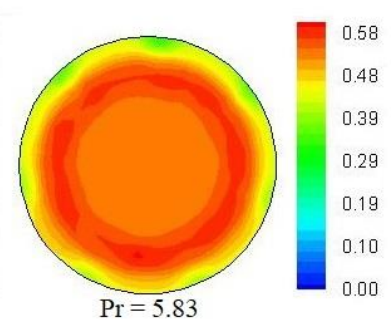

Figure 4. Particulates concentration contour at $V_{m}=5 \mathrm{~ms}^{-1}$ for different Prandtl number at a) $C_{v f}=30 \%$, b) $C_{v f}=40 \%$, and c) $C_{v f}=50 \%$ 


\section{Velocity Contours}

Figure 5(a) depicts the velocity contours of solid phase for different Prandtl numbers at solid concentration, $C_{v f}=30 \%$ and mean flow velocity, $V_{m}=3 \mathrm{~ms}^{-1}$. It has been found that the solid phase velocity is maximum at the center of the pipeline for chosen mean flow velocity and solid concentration range for all Prandtl numbers. The effect on velocity contours varies with increases in solid concentration and Prandtl number. At low Prandtl number, the velocity contours are asymmetric about the center of the pipeline as depicted in the Figure 5(a) for $\operatorname{Pr}=1.34, \operatorname{Pr}=2.14$ and $\operatorname{Pr}=3.42$. However, as the Prandtl number increases the symmetry increases as depicted in the Figure 5(a) for $\operatorname{Pr}=5.83$. Moreover, with increase in solid concentration the symmetry increases as depicted in the Figure 5(b) and 5(c). The velocity contours in Figure 5(c) are more symmetrical than Figure 5(b). The change in velocity contours about the center of the pipeline results due to variation in viscosity of slurry mixture for different Prandtl numbers that increases/decreases the turbulence and momentum exchange between the solid particulates. Further, it leads to dispersion of solid particulates throughout the domain and thereby increases the symmetry about the center of the pipeline. Similar effects can also be observed at higher velocity for different solid concentration range and Prandtl number as depicted in the Figure 6(a-c) and 7 (a-c).

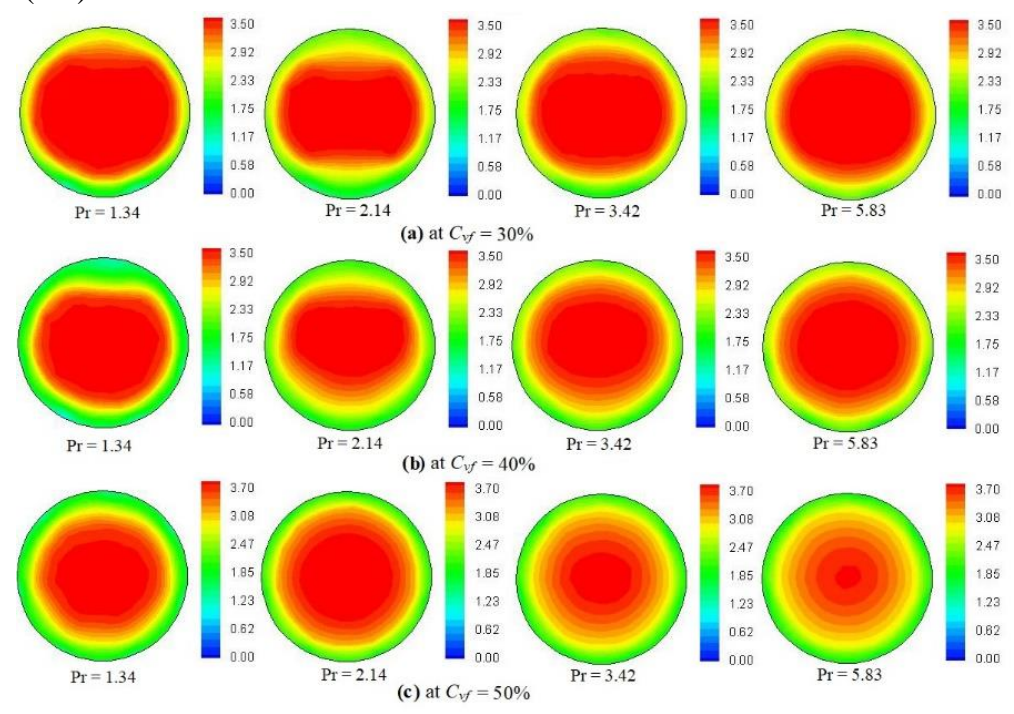

Figure 5. Velocity contours at $V_{m}=3 \mathrm{~ms}^{-1}$ for different Prandtl number at a) $C_{v f}=30 \%$, b) $C_{v f}=40 \%$, and c) $C_{v f}=50 \%$

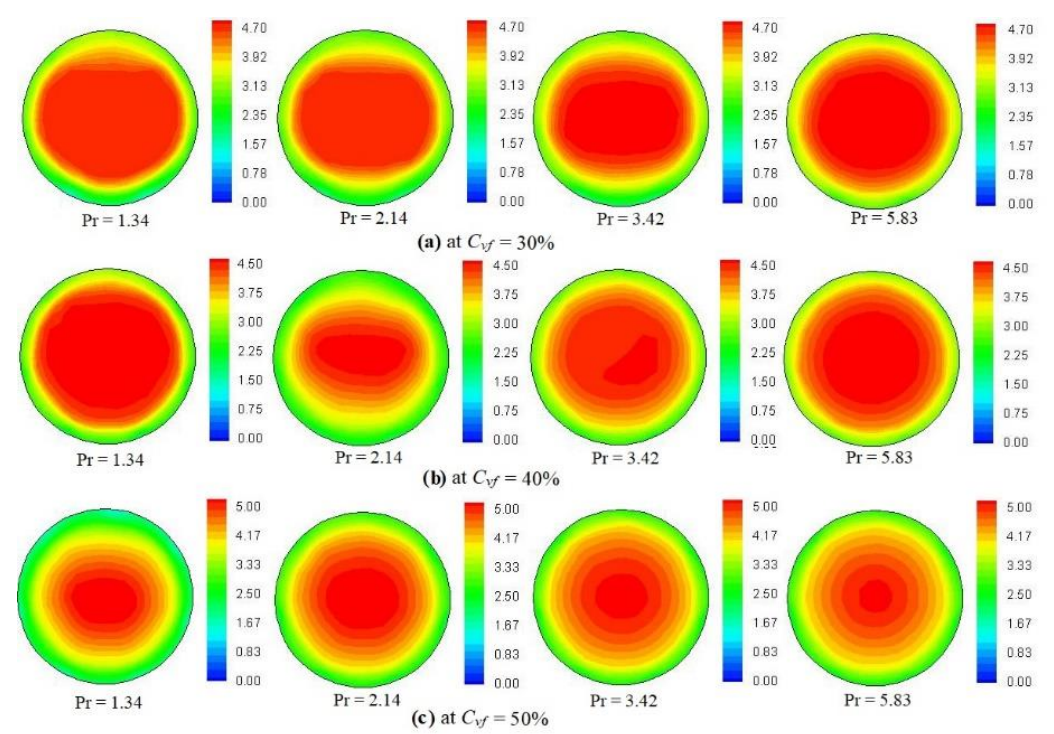

Figure 6. Velocity contours at $V_{m}=4 \mathrm{~ms}^{-1}$ for different Prandtl number at a) $C_{v f}=30 \%$, b) $C_{v f}=40 \%$, and c) $C_{v f}=50 \%$ 


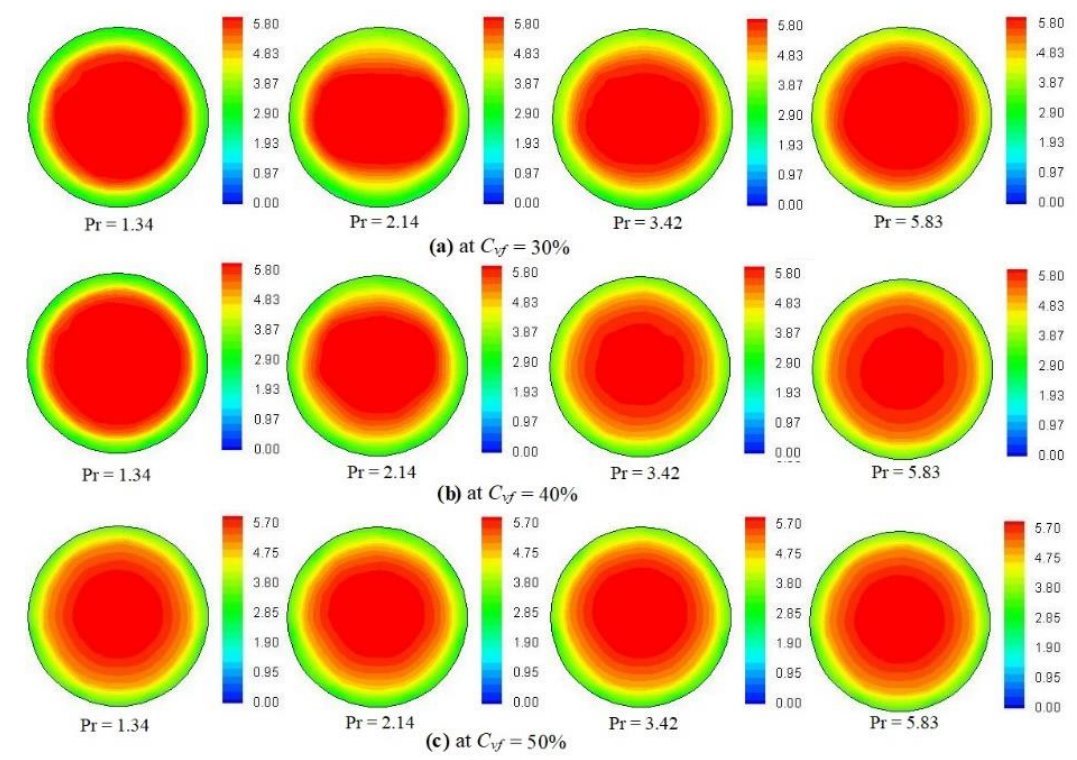

Figure 7. Velocity contours at $V_{m}=5 \mathrm{~ms}^{-1}$ for different Prandtl number at a) $C_{v f}=30 \%$, b) $C_{v f}=40 \%$, and c) $C_{v f}=50 \%$

\section{Solid Concentration Profiles}

Figure 8 (a-c) depicts the solid concentration profile in the $x y$ plane at a distance, $x=3.7 \mathrm{~m}$ from the pipe inlet for different Prandtl number at $V_{m}=3 \mathrm{~ms}^{-1}$ and $C_{v f}=30-50 \%$. It has been observed that solid concentration decreases from bottom to top of the pipeline for all chosen Prandtl numbers. However, the solid concentration profile at low Prandtl number succeeds the other solid concentration profile at higher Prandtl numbers through the marked arrow $\left(\alpha_{\mathrm{s}}\right)$ as depicted in the Figure 8. The thickness of the fluidized bed decreases at higher Prandtl number in the lower half of the pipeline. It is further observed that a feeble effect in concentration profile is seen at higher solid concentration, $C_{v f}=50 \%$. Similar effects can also be observed for higher velocity and solid concentration range for different Prandtl numbers as depicted in the Figure 9(a-c) and $10(\mathrm{a}-\mathrm{c})$.

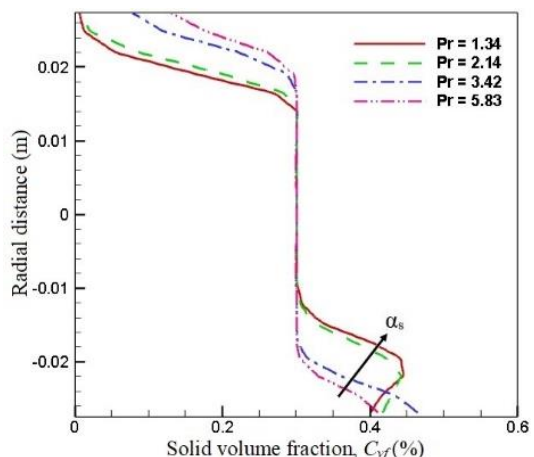

a)

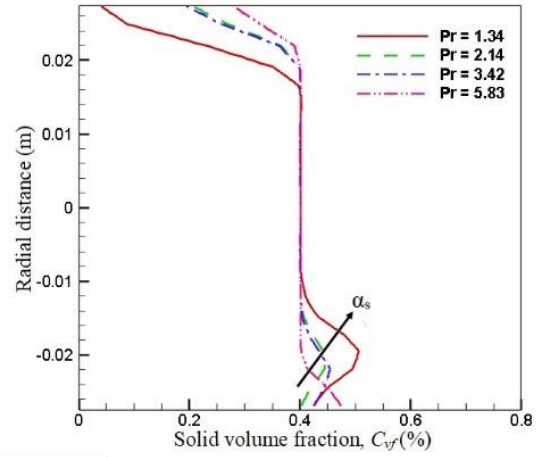

b)

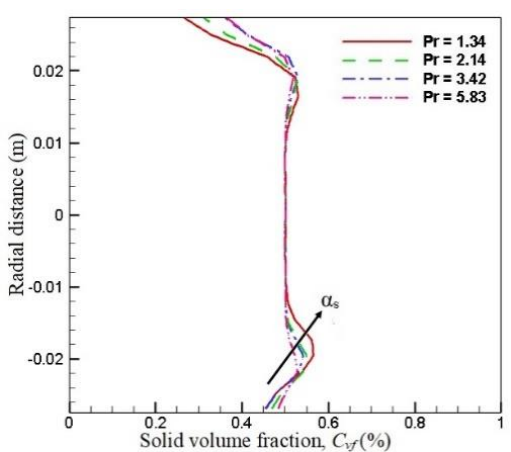

c)

Figure 8. Particulates concentration profiles in xy plane for different Prandtl number at $V_{m}=3 \mathrm{~ms}^{-1}$ at a) $C_{v f}=$ $30 \%$, b) $C_{v f}=40 \%$, and c) $C_{v f}=50$ 
Journal of Thermal Engineering, Research Article, Vol. 7, No. 4, pp. 867-885, May, 2021
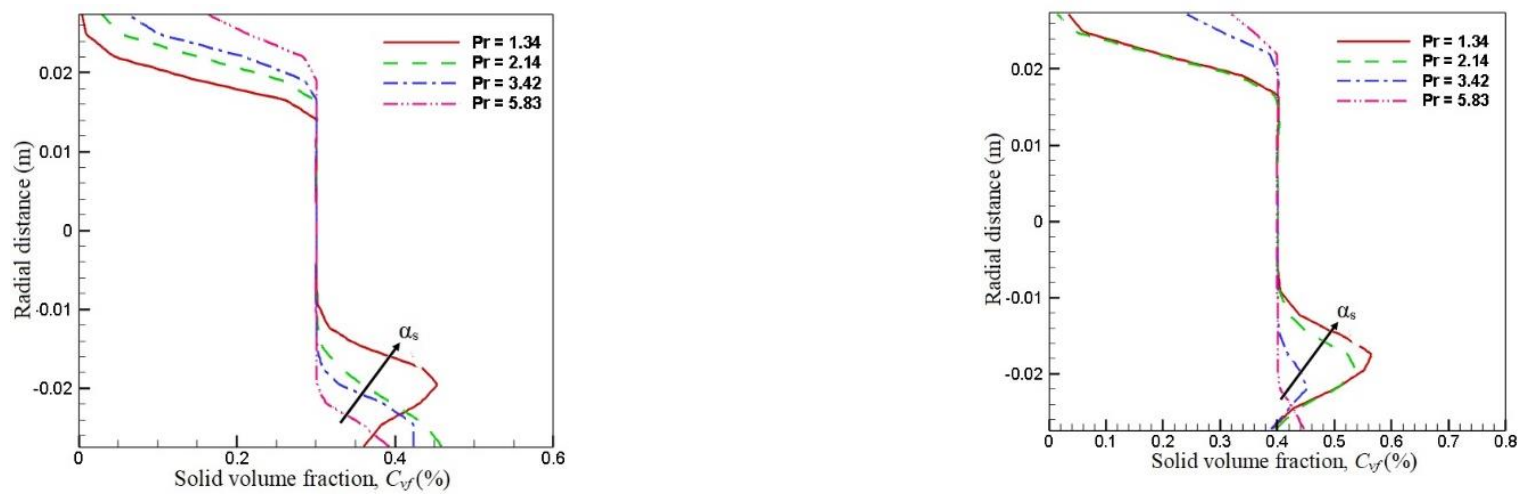

a)

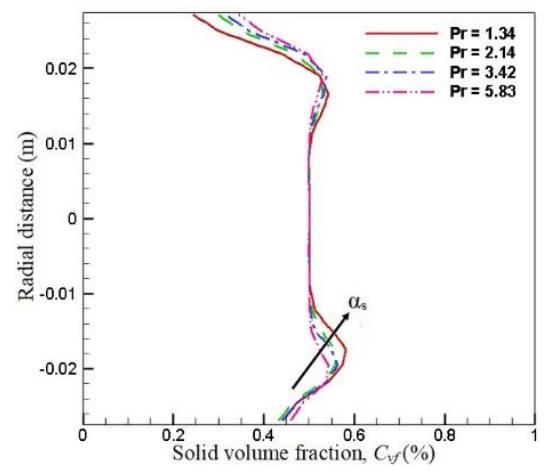

b)

c)

Figure 9. Particulates concentration profiles in xy plane for different Prandtl number at $V_{m}=4 \mathrm{~ms}^{-1}$ at a) $C_{v f}=$ $30 \%$, b) $C_{v f}=40 \%$, and c) $C_{v f}=50 \%$
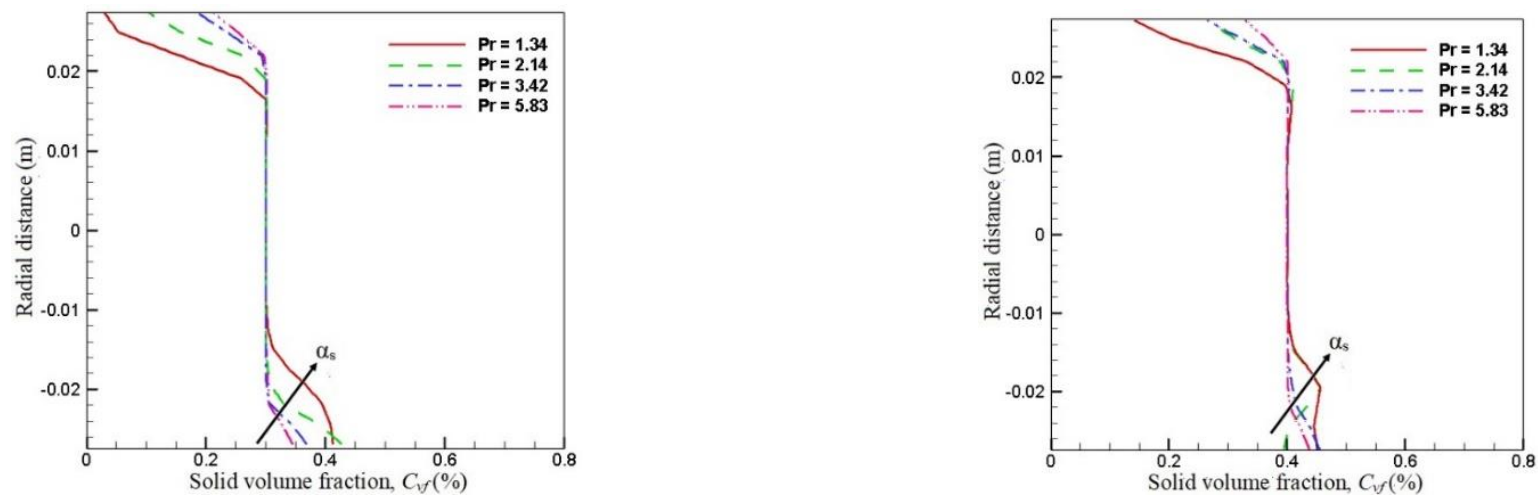

a)

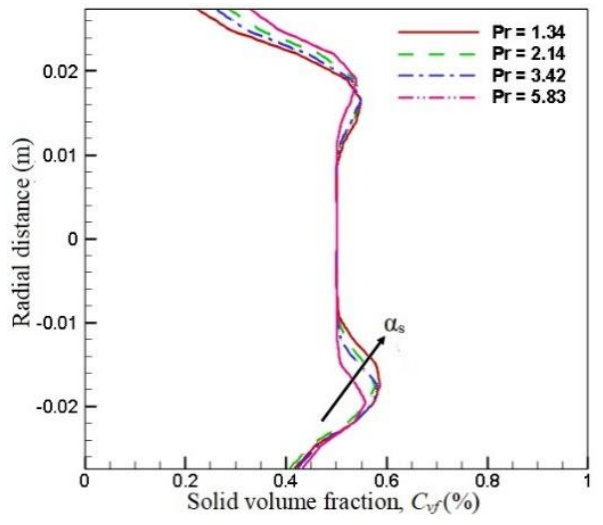

b)

c)

Figure 10. Particulates concentration profiles in xy plane for different Prandtl number at $V_{m}=5 \mathrm{~ms}^{-1}$ at a) $C_{v f}$ $=30 \%$, b) $C_{v f}=40 \%$, and c) $C_{v f}=50 \%$ 


\section{Velocity profile}

Figure 11 (a-c) depicts the solid phase velocity profile in $x-y$ plane at a distance, $x=3.7 \mathrm{~m}$ from the pipe inlet for different Prandtl numbers at mean velocity range, $V_{m}=3-5 \mathrm{~ms}^{-1}$ and solid concentration range, $C_{v f}$ $=30-50 \%$. It has been found that the velocity profiles are flatten in nature at lower solid concentration, i.e. $C_{v f}$ $=30-40 \%$ for all velocities and Prandtl number as depicted in the Figures 11 (a-b), 12 (a-b) and 13 (a-b). However, the velocity profile tends to parabolic in nature at higher solid concentration, $\left(C_{v f}=50 \%\right)$ as depicted in the Figure 11(c), 12(c) and 13(c).
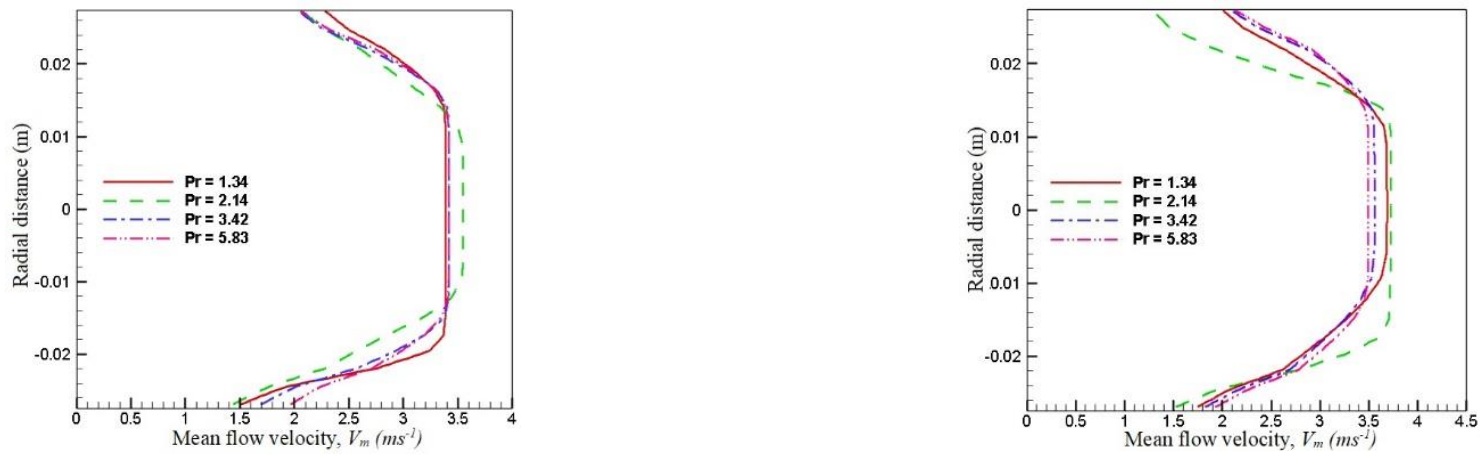

a)

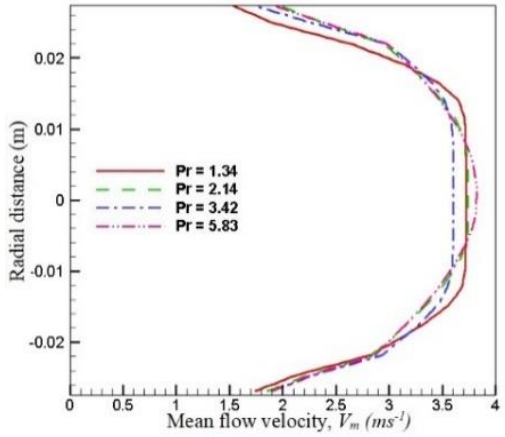

b)

c)

Figure 11. Velocity profiles in xy plane for different Prandtl number at $V_{m}=3 \mathrm{~ms}^{-1}$ at a) $C_{v f}=30 \%$, b) $C_{v f}=$ $40 \%$, and c) $C_{v f}=50 \%$

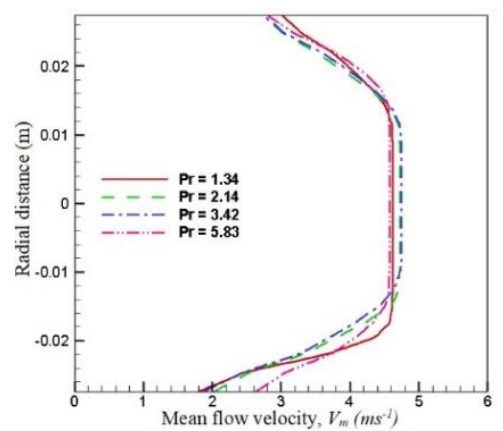

a)

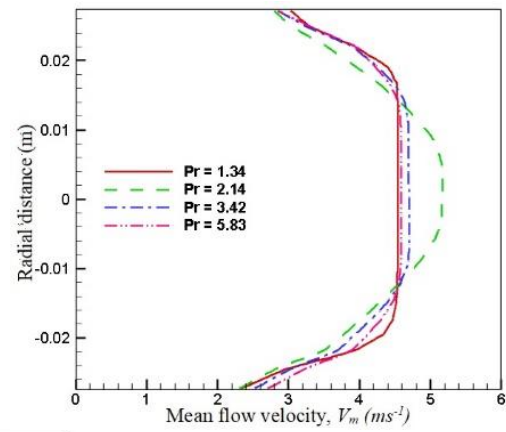

b)

c)

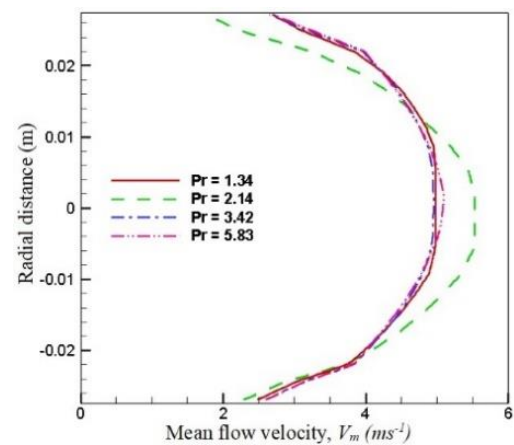

Figure. 12. Velocity profiles in xy plane for different Prandtl number at $V_{m}=4 \mathrm{~ms}^{-1}$ at a) $C_{v f}=30 \%$, b) $C_{v f}=$ $40 \%$, and c) $C_{v f}=50 \%$ 

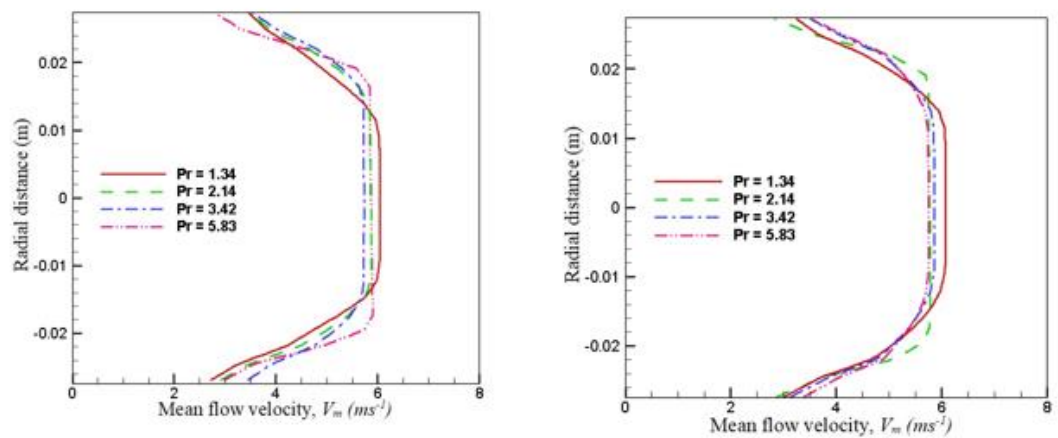

a)

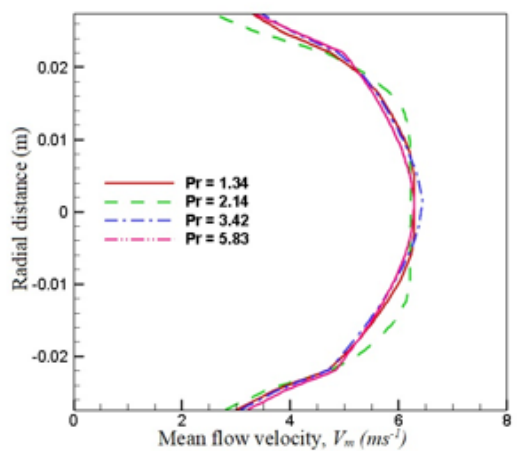

b)

c)

Figure 13. Velocity profiles in xy plane for different Prandtl number at $V_{m}=5 \mathrm{~ms}^{-1}$ at a) $C_{v f}=30 \%$, b) $C_{v f}=40$ $\%$, and c) $C_{v f}=50 \%$

\section{Pressure Drop}

Figure 14 a-c depicts the pressure drop variation with mean flow velocity at different Prandtl numbers and solid concentration. It is found that the pressure drop rises with rise in velocity and Prandtl number at all solid concentration range. At higher solid concentration, turbulence mixing intensifies that causes the greater pressure loss across the pipeline.
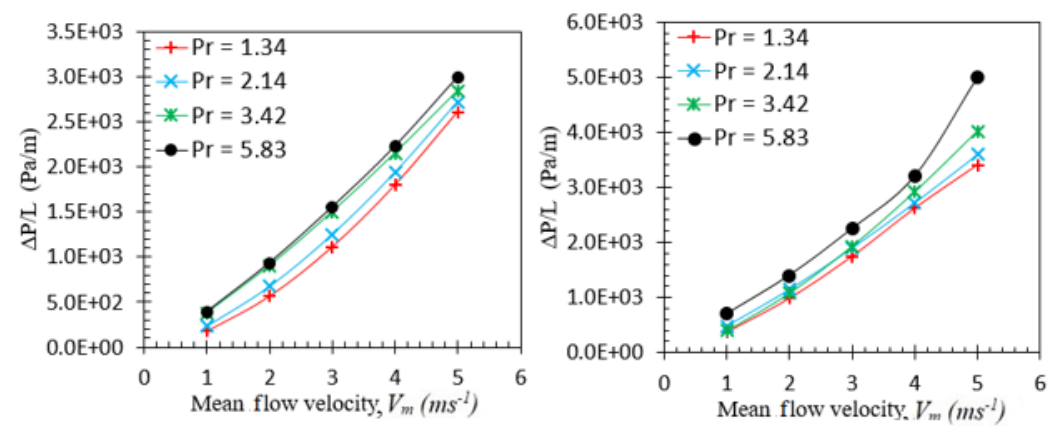

a)

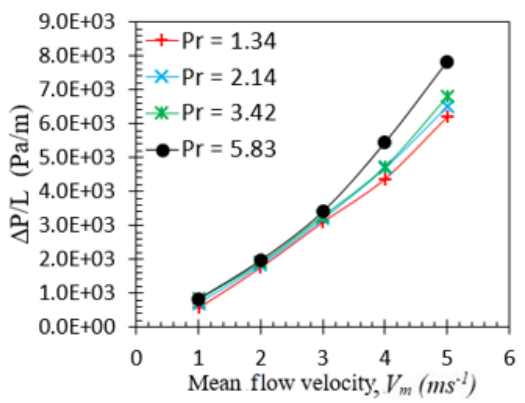

b)

c)

Figure 14. Variation of pressure drop with mean flow velocity for different Prandtl numbers at a) $C_{v f}=30 \%$, b)

$$
C_{v f}=40 \% \text {, and c) } C_{v f}=50 \%
$$




\section{MODEL VALIDATION}

Figure 15(a-d) depicts the validation of the developed computational model for different Prandtl number with the published data by Kaushal et al. (2007) [18] at $C_{v f}=50 \%$. The finding show that the pressure drop line at low Prandtl number is in synchronism with the published pressure drop line as depicted in the Figure 15 (a-c). Pressure drop is the important parameter for the slurry pipeline design system at different operating conditions. Therefore, the present computational model at different Prandtl numbers help the pipe designer to better know the slurry flow behavior across the pipeline system.

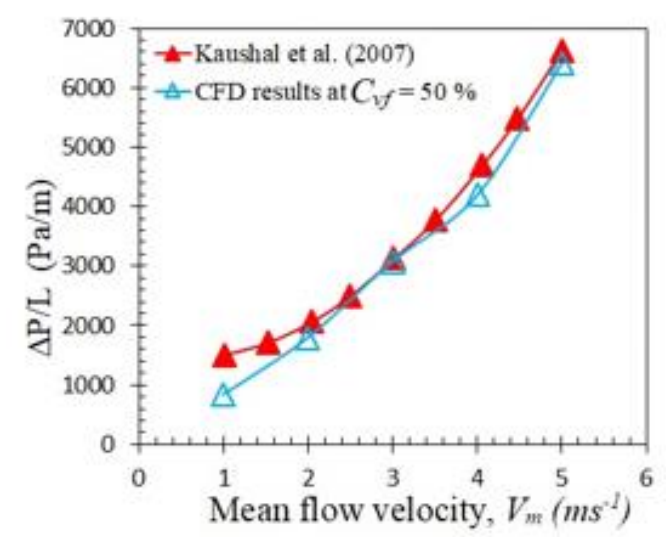

a)

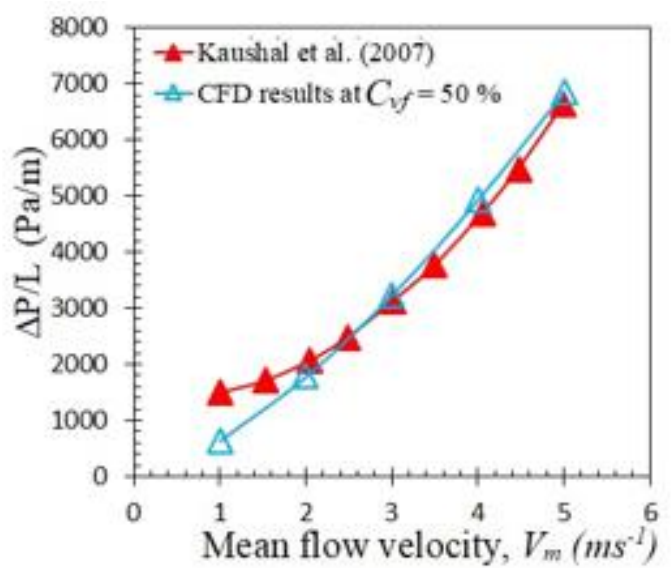

c)

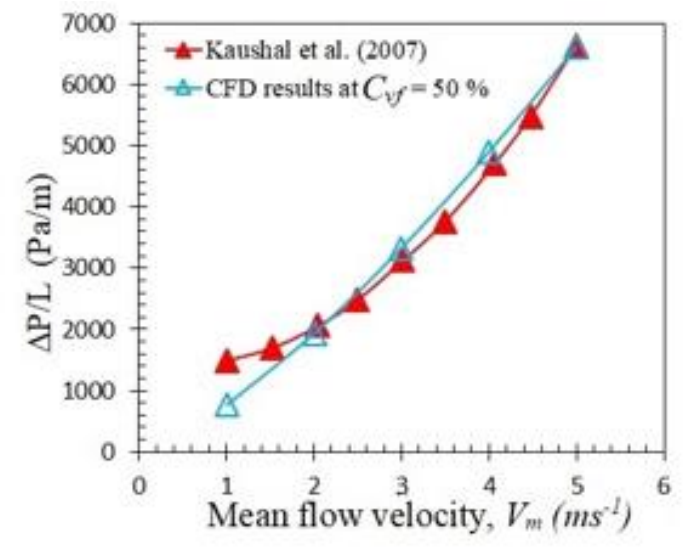

b)

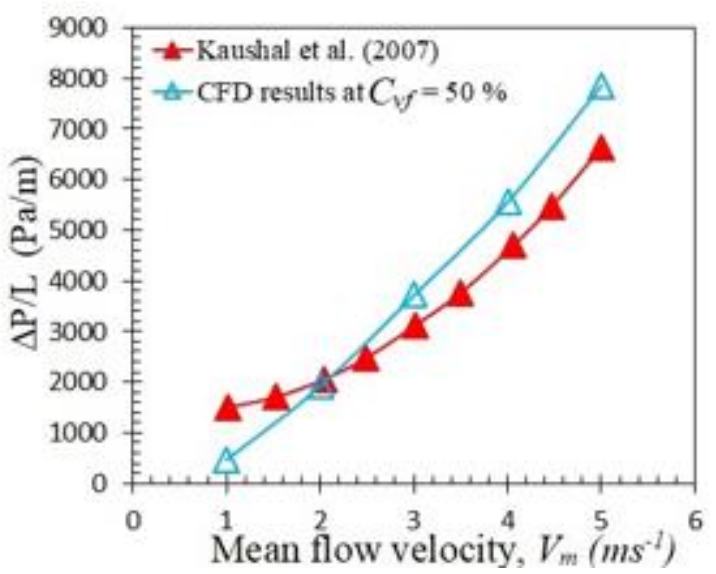

d)

Figure 15. Validation of Pressure drop at different Prandtl number a) $\operatorname{Pr}=1.34$, b) $\operatorname{Pr}=2.14$, c) $\operatorname{Pr}=3.42$, and d) $\operatorname{Pr}=5.83$

\section{CONCLUSION}

The concluding remarks of present work on the solid-water slurry flow at different Prandtl fluids are as follows:

- The Eulerian two-phase model of FLUENT was found to be appropriately capture the flow behavior of slurry transport through pipeline for chosen flow velocity and solid concentration range at different Prandtl number.

- The suspension stability of solid particulates at low Prandtl number, $\operatorname{Pr}=1.34$ is found more as compared to the higher values of Prandtl number.

- The thickness of the fluidized bed moving at the bottom of the pipeline is found more at low Prandtl number and it decreases with the rise in Prandtl number.

- The particulates concentration is found more at the pipe bottom at all Prandtl number and it decreases from bottom to top of the pipeline. 
- The glass beads exhibit maximum velocity at the center of the pipeline and minimum velocity near the pipe wall due to the effect of viscous forces.

- The velocity profiles is found flatten in nature at lower solid concentration, which in turn becomes parabolic in nature at higher solid concentration.

- The pressure drop rises with increase in Prandtl number at all velocity and solid concentration range.

The study gives the satisfactory results with the published data in the literature and the transportation capability is high at Prandtl number, $\operatorname{Pr}=1.34$. Therefore, it is better for the design engineer to transport the solid particulates with fluid properties at $\mathrm{Pr}=1.34$ for minimizing the pressure drop.

\section{NOMENCLATURE}

$C_{v f} \quad$ Efflux concentration, by volume

D Diameter of pipe, $m$

$\mathrm{d}_{\mathrm{s}} \quad$ Particle diameter, $\mu \mathrm{m}$

$\mathrm{g} \quad$ Acceleration due to gravity, $\mathrm{m} / \mathrm{s}^{2}$

$\overrightarrow{v_{s}} \quad$ Velocity of solid phase, $\mathrm{m} / \mathrm{s}$

$\overrightarrow{v_{f}} \quad$ Velocity of fluid phase, $\mathrm{m} / \mathrm{s}$

$\mathrm{C}_{\mathrm{vm}} \quad$ Coefficient of virtual mass

$\rho \quad$ Mass density, $\mathrm{kg} / \mathrm{m}^{3}$

$\rho_{\mathrm{f}} \quad$ Mass density for fluid phase, $\mathrm{kg} / \mathrm{m}^{3}$

$\rho_{\mathrm{s}} \quad$ Mass density for solid phase, $\mathrm{kg} / \mathrm{m}^{3}$

$\mathrm{C}_{\mathrm{L}} \quad$ Lift force

$\mathrm{V}_{\mathrm{m}} \quad$ Mean flow velocity, $\mathrm{m} / \mathrm{s}$

$\operatorname{Re}_{\mathrm{s}} \quad$ Relative Reynold number between solid and fluid phase

$\overline{\bar{I}} \quad$ Identity tensor

$\lambda_{s} \quad$ Bulk viscosity of solid phase

$\overline{\overline{\tau_{f}}} \quad$ viscous stress tensor for fluid phase

$\mathrm{g}_{\mathrm{o}, \mathrm{ss}} \quad$ Radial distribution function

$\mu_{\mathrm{s}} \quad$ Shear viscosity for solid phase, $\mathrm{Pa}$-s

$\mu_{\mathrm{f}} \quad$ Shear viscosity for fluid phase, $\mathrm{Pa}-\mathrm{s}$

$\mu_{\mathrm{s}, \mathrm{col}} \quad$ collisional viscosity

$\mu_{\mathrm{s}, \mathrm{kin}} \quad$ kinetic viscosity

$\mu_{\mathrm{s}, \mathrm{fr}} \quad$ frictional viscosity

$\mathrm{C}_{\mathrm{D}} \quad$ Drag coefficient

$\mathrm{e}_{\mathrm{ss}} \quad$ Restitution coefficient

$\Theta_{\mathrm{s}} \quad$ Granular temperature

$\mathrm{I}_{2 \mathrm{D}} \quad$ Second invariant strain rate tensor for solid phase

$\mathrm{K}_{\text {sf }} \quad$ Inter-phasial momentum exchange coefficient

$\mathrm{V}_{\mathrm{r}, \mathrm{s}} \quad$ Terminal velocity for solid phase, $\mathrm{ms}^{-1}$

Greek symbols

$\alpha_{s, \max } \quad$ Static settled concentration,

$\alpha_{s} \quad$ Solid phase concentration

$\alpha_{\mathrm{f}} \quad$ Liquid phase concentration

Subscripts

f Refers to fluid

s Refers to solid

\section{REFERENCES}

[1] O'Brien, MP. Review of the theory of turbulent flow and its relations to sediment transportation. Transactions American Geophysical Union 1933; 14: 487-491. https://doi.org/10.1029/TR014i001p00487

[2] Rouse, H. Modern conceptions of the mechanics of fluid turbulence. Transactions ASCE, 1937; 102: 463505 .

[3] Ismail, HM. Turbulent transfer mechanism and suspended sediment in closed channels. Transactions ASCE. 1952; 117: 409-446 
[4] Shook, CA. Daniel, S. M. Flow of suspensions of solids in pipeline: Flow with a stable stationary deposit. Can J Chem Eng, 1965; 43:56-72. https://doi.org/10.1002/cjce.5450430202.

[5] Shook, CA, Daniel, SM, Scott, JA, Holgate, JP. Flow of suspensions in pipelines. Can J Chem Eng 1968; 46: 238-244. https://doi.org/10.1002/cjce.5450460405

[6] Karabelas, AJ. Vertical distribution of dilute suspensions in turbulent pipe flow. AIChE J 1977; 23: 426434. https://doi.org/10.1002/aic.690230404.

[7] Turian, RM, Hsu, FL, Selim, MS. Friction losses for flow of slurries in pipeline bends, fittings, and valves. Particul Sci Technol 1983; 1(4): 365-392. https://doi.org/10.1080/02726358308906383.

[8] Roco, MC, Shook, CA. Modeling of slurry flow: The effect of particle size. Can J Chem Eng 1983; 61:494503. https://doi.org/10.1002/cjce.5450610402.

[9] Roco, MC, Shook, CA. Computational methods for coal slurry pipeline with heterogeneous size distribution. Powder Technol 1984; 39:159-176. https://doi.org/10.1016/0032-5910(84)85034-2.

[10] Colwell, JM, Shook, CA. The entry length for slurries in horizontal pipeline flow. Can J Chem Eng 1988; 66(5):714-720. https://doi.org/10.1002/cjce.5450660503.

[11] Gillies, RG, Shook, CA, Wilson, KC. An improved two-layer model for horizontal slurry pipeline flow. Can J Chem Eng 1991; 69: 173-178. https://doi.org/10.1002/cjce.5450690120.

[12] Gillies, RG, Hill KB, Mckibben, MJ, Shook, CA. Solids transport by laminar Newtonian flows. Powder Technol 1999; 104:269-277. https://doi.org/10.1016/S0032-5910(99)00104-7.

[13] Gillies, RG, Shook, CA. Modeling high concentration settling slurry flows. Can J Chem Eng 200; 78:709716. https://doi.org/10.1002/cjce.5450780413.

[14] Matousek, V. Pressure drops and flow patterns in sand-mixture pipes. Exp Therm Fluid Sci 2002; 26(6):693-702. https://doi.org/10.1016/S0894-1777(02)00176-0.

[15] Ling, J, Skudarnov, PV, Lin, CX. Ebadian, M. A. Numerical investigations of liquid solid slurry flows in a fully developed turbulent flow region. International Journal of Heat and Fluid Flow 2003; 24:389-398. https://doi.org/10.1016/S0142-727X(03)00018-3.

[16] Krampa-Morlu, FN, Bergstrom, D.J, Bugg, JD, Sanders, RS, Schaan, J. Numerical simulation of dense coarse particle slurry flows in a vertical pipe. In 5th International Conference on Multiphase flow, ICMF 2004; 4:460.

[17] Kaushal, DR; Sato, K, Toyota, T, Funatsu, K, Tomita, Y. Effect of particle size distribution on pressure drop and concentration profile in pipeline flow of highly concentrated slurry. Int J Multiphas Flow 2005; 31: 809-823. https://doi.org/10.1016/j.ijmultiphaseflow.2005.03.003.

[18] Kaushal, DR, Tomita, Y. Experimental investigation for near-wall lift of coarser particles in slurry pipeline $\begin{array}{llll}\text { using } & \gamma \text {-ray } \quad \text { densitometer. Powder } & \text { Technol } & \text { 2007; }\end{array}$ https://doi.org/10.1016/j.powtec.2006.11.020.

[19] Lin, CX. Ebadian, MA. A numerical study of developing slurry flow in the entrance region of a horizontal pipe. Comput Fluids 2008; 37(8):965-974. https://doi.org/10.1016/j.compfluid.2007.10.008.

[20] Lahiri, SK, Ghanta, KC. Prediction of pressure drop of slurry flow in pipeline by hybrid support vector regression and genetic algorithm model. Chin J Chem Eng 2008; 16(6): 841-848. https://doi.org/10.1016/S1004-9541(09)60003-3.

[21] Kumar, A, Kaushal, DR, Kumar, U. Bend pressure drop experiments compared with FLUENT. Proceedings of the Institution of Civil Engineers-Engineering and Computational Mechanics 2008; 161(1): 35-42. https://doi.org/10.1680/eacm.2008.161.1.35.

[22] Chandel, S, Seshadri, V, Singh, SN. Effect of additive on pressure drop and rheological characteristics of fly ash slurry at high concentration. Particul Sci Technol 2009; 27(3):271-284. https://doi.org/10.1080/02726350902922036.

[23] Monteiro, AC, Bansal, PK. Pressure drop characteristics and rheological modeling of ice slurry flow in pipes. Int J Refrig 2010; 33(8):1523-1532. https://doi.org/10.1016/j.ijrefrig.2010.09.009.

[24] Naik, HK, Mishra, MK, Rao, KU. Influence of chemical reagents on rheological properties of fly ash-water slurry at varying temperature environment. Coal Combustion and Gasification Products 2011; 3:83-93.

[25] Kaushal, DR, Thinglas, T, Tomita, Y, Kuchii, S, Tsukamoto, H. CFD modeling for pipeline flow of fine particles at high concentration. Int J Multiphas Flow 2012; 43: 85-100. https://doi.org/10.1016/j.ijmultiphaseflow.2012.03.005.

[26] Kaushal, DR, Kumar, A, Tomita, Y, Kuchii, S, Tsukamoto, H. Flow of mono-dispersed particles through horizontal bend. Int J Multiphas Flow 2013; https://doi.org/10.1016/j.ijmultiphaseflow.2012.12.009.

[27] Gopaliya, MK, Kaushal, DR. Modeling of sand-water slurry flow through horizontal pipe using CFD. J Hydrol Hydromech 2016; 64(3): 261-272.

[28] Melorie, AK, Kaushal, DR. Experimental Investigations of the Effect of Chemical Additives on the Rheological Properties of Highly Concentrated Iron Ore Slurries. KONA Powder Part J. 2017; 35:186-199. https://doi.org/10.14356/kona.2018001 
[29] Assefa, KM, Kaushal DR. A new model for the viscosity of highly concentrated multi-sized particulate $\begin{array}{lllll}\text { Bingham Slurries. } & \text { Particul } & \text { Sci } & \text { Technol } & \text { 2017; }\end{array}$ https://doi.org/10.1080/02726351.2015.1131789.

[30] Singh, JP, Kumar, S, Mohapatra, SK. Modelling of two-phase solid-liquid flow in horizontal pipe using computational fluid dynamics technique. Int J Hydrogen Energy 2017; 42(31): 20133-20137. https://doi.org/10.1016/j.ijhydene.2017.06.060.

[31] Singh, MK, Kumar, S, Ratha, D, Kaur, H. Design of slurry transportation pipeline for the flow of multiparticulate coal ash suspension. Int J Hydrogen Energy 2017; 42 (30):19135-19138.

[32] Parkash, O, Kumar, A, Sikarwar, BS, CFD Modeling of Commercial Slurry Flow through Horizontal Pipeline. In Advances in Interdisciplinary Engineering. Springer, Singapore 2019; 153-162. https://doi.org/10.1007/978-981-13-6577-5_16.

[33] Hoseinzadeh, S, Ghasemiasl, Havaei, D, Chamkha, AJ. Numerical investigation of rectangular thermal energy storage units with multiple phase change materials. J Mol Liq 2018; 271: 655-660. https://doi.org/10.1016/j.molliq.2018.08.128.

[34] Hoseinzadeh, S, Heyns, PS, Chamkha, AJ, Shirkhani, A. Thermal analysis of porous fins enclosure with the comparison of analytical and numerical methods. J Therm Anal Calorim 2019; 1-9.

[35] Hoseinzadeh, S, Moafi, A, Shirkhani, A, Chamkha, AJ. Numerical Validation Heat Transfer of Rectangular Cross-Section Porous Fins. Journal of Thermophysics and Heat Transfer 2019; 1-7. https://doi.org/10.2514/1.T5583

[36] Hoseinzadeh, S, Hadi Zakeri, M, Shirkhani, A, Chamkha, AJ. Analysis of energy consumption improvements of a zero-energy building in a humid mountainous area. J Renew Sustain Ener 2019; 11(1):015103. https://doi.org/10.1063/1.5046512.

[37] Kohzadia, H, Shadarama, A, Hoseinzadeh S. Improvement of the centrifugal pump performance by restricting the cavitation phenomenon. Chem Eng 2018;71. https://doi.org/10.3303/CET1871229

[38] Javadi, MA, Hoseinzadeh, S, Khalaji, M, Ghasemiasl, R. Optimization and analysis of exergy, economic and environmental of a combined cycle power plant. Sādhanā 2019; 44(5):121.,

[39] Ma, Y, Mohebbi, R, Rashidi, MM, Yang, Z. MHD convective heat transfer of Ag-MgO/water hybrid nanofluid in a channel with active heaters and coolers. Int J Heat Mass Transf 2019; 137: 714-726. https://doi.org/10.1016/j.ijheatmasstransfer.2019.03.169.

[40] Ma, Y, Mohebbi, R, Rashidi, MM, Manca, O, Yang, Z. Numerical investigation of MHD effects on nanofluid heat transfer in a baffled U-shaped enclosure using lattice Boltzmann method. J Therm Anal Calorim 2019; 135(6):3197-3213.

[41] Ma, Y, Mohebbi, R, Rashidi, MM, Yang, Z, Sheremet, MA. Numerical study of MHD nanofluid natural convection in a baffled U-shaped enclosure. Int J Heat Mass Transf 2019; 130, 123-134. https://doi.org/10.1016/j.ijheatmasstransfer.2018.10.072.

[42] Mansoury, D, Doshmanziari, FI, Rezaie, S, Rashidi, MM. Effect of Al2O3/water nanofluid on performance of parallel flow heat exchangers. J Therm Anal Calorim 2019; 135(1): 625-643.

[43] Bhatti, MM, Mishra, SR, Abbas, T, Rashidi, MM. A mathematical model of MHD nanofluid flow having gyrotactic microorganisms with thermal radiation and chemical reaction effects. Neural Comput Appl 2018; 30(4): 1237-1249.

[44] Sheikholeslami, M, Jafaryar, M, Hedayat, M, Shafee, A, Li, Z, Nguyen, TK, Bakouri, M. Heat transfer and turbulent simulation of nanomaterial due to compound turbulator including irreversibility analysis. Int $\mathbf{J}$ Heat Mass Transfer 2019; 137: 1290-1300. https://doi.org/10.1016/j.ijheatmasstransfer.2019.04.030.

[45] Sheikholeslami, M, Jafaryar, M, Shafee, A, Li, Z, Haq, RU. Heat transfer of nanoparticles employing innovative turbulator considering entropy generation. Int J Heat Mass Transf 2019; 136: 1233-1240. https://doi.org/10.1016/j.ijheatmasstransfer.2019.03.091.

[46] Sheikholeslami, M, Haq, RU, Shafee, A, Li, Z, Elaraki, YG, Tlili, I. Heat transfer simulation of heat storage unit with nanoparticles and fins through a heat exchanger. Int J Heat Mass Transf 2019; 135: 470-478. https://doi.org/10.1016/j.ijheatmasstransfer.2019.02.003.

[47] Sheikholeslami, M, Haq, RU, Shafee, A, Li, Z. Heat transfer behavior of nanoparticle enhanced PCM solidification through an enclosure with V shaped fins. Int J Heat Mass Transf 2019; 130: 1322-1342. https://doi.org/10.1016/j.ijheatmasstransfer.2018.11.020.

[48] Sheikholeslami, M. New computational approach for exergy and entropy analysis of nanofluid under the impact of Lorentz force through a porous media. Comput Methods Appl Mech Eng 2019; 344:319-333. https://doi.org/10.1016/j.cma.2018.09.044.

[49] Sheikholeslami, M. Numerical approach for MHD Al2O3-water nanofluid transportation inside a permeable medium using innovative computer method. Comput Methods Appl Mech Eng 2019; 344:306-318. https://doi.org/10.1016/j.cma.2018.09.042.

[50] Sheikholeslami, M, Gerdroodbary, MB, Moradi, R, Ahmad, S, Zhixiong, Li. Application of Neural Network 
for estimation of heat transfer treatment of AlO-HO nanofluid through a channel. Comput Methods Appl Mech Eng 2019; 344:1-12.

[51] Sheikholeslami, M, Mahian, O. Enhancement of PCM solidification using inorganic nanoparticles and an external magnetic field with application in energy storage systems. J Clean Prod 2019; 215: 963-977. https://doi.org/10.1016/j.jclepro.2019.01.122.

[52] Sheikholeslami, M, Arabkoohsar, A, Khan, I, Shafee, A, Li, Z. Impact of Lorentz forces on Fe3O4 water ferrofluid entropy and exergy treatment within a permeable semi annulus. J Clean Prod 2019; 221: 885898. https://doi.org/10.1016/j.jclepro.2019.02.075.

[53] Sheikholeslami, M, Shafee, A, Zareei, A, Haq, RU, Li, Z. Heat transfer of magnetic nanoparticles through porous media including exergy analysis. J Mol Liq 2019; 279, 719-732. https://doi.org/10.1016/j.molliq.2019.01.128.

[54] Sheikholeslami, M, Jafaryar, M, Shafee, A, Li, Z. Simulation of nanoparticles application for expediting melting of PCM inside a finned enclosure. Physica A: Statistical Mechanics and its Applications 2019; 523: 544-556. https://doi.org/10.1016/j.physa.2019.02.020.

[55] Jajja, SA, Ali, W, Ali, HM, Ali, AM. Water cooled minichannel heat sinks for microprocessor cooling: Effect of fin spacing. Appl Therm Eng 2014; 64: 76-82. https://doi.org/10.1016/j.applthermaleng.2013.12.007

[56] Jajja, SA, Ali, W, Ali, HM. Multiwalled carbon nanotube nanofluid for thermal management of high heat generating computer processor. Heat Transfer-Asian Research 2014;43(7): 653-666. https://doi.org/10.1002/htj.21107.

[57] Ali, HM, Ali, H, Liaquat, H, Maqsood, HTB, Nadir, MA. Experimental investigation of convective heat transfer augmentation for car radiator using $\mathrm{ZnO}$-water nanofluids. Energy 2015; 84: 317-324. https://doi.org/10.1016/j.energy.2015.02.103

[58] Ali, H., Azhar, MD., Saleem, M, Saeed, QS, Saieed, A. Water based Mgo nanofluids for thermal management of car radiator. Journal of Thermal Science 2015; 19(6): 2039-2048.

[59] Siddiqui, AM, Arshad, W, Ali, HM, Ali, M, Nasir, MA. Evaluation of nanofluids performance for simulated microprocessor. Therm Sci 2017; 21(5). https://doi.org/10.2298/TSCI150131159S.

[60] Ali, HM, Arshad, W. Thermal performance investigation of staggered and inline pin fin heat sinks using water based rutile and anatase TiO2 nanofluids. Energ Convers Manage 2015; 106: 793-803. https://doi.org/10.1016/j.enconman.2015.10.015.

[61] Ali, HM, Arshad, W. Effect of channel angle of pin-fin heat sink on heat transfer performance using water based graphene nanoplatelets nanofluids. Int J Heat Mass Transf 2017; 106: 465-472. https://doi.org/10.1016/j.ijheatmasstransfer.2016.08.061.

[62] Arshad, W, Ali, HM. Graphene nanoplatelets nanofluids thermal and hydrodynamic performance on integral fin heat sink. Int J Heat Mass Transf 2017; 107: 995-1001. https://doi.org/10.1016/j.ijheatmasstransfer.2016.10.127.

[63] Arshad, W, Ali, HM. Experimental investigation of heat transfer and pressure drop in a straight minichannel heat sink using TiO2 nanofluid. Int J Heat Mass Transf 2017; 110: 248-256. https://doi.org/10.1016/j.ijheatmasstransfer.2017.03.032.

[64] Ali, H, Babar, H, Shah, T, Sajid, M, Qasim, M, Javed, S. Preparation techniques of TiO2 nanofluids and challenges: a review. Applied Sciences 2018; 8(4): 587. https://doi.org/10.3390/app8040587.

[65] Sajid, MU, Ali, HM. Thermal conductivity of hybrid nanofluids: a critical review. Int J Heat Mass Transf 2018; 126: 211-234. https://doi.org/10.1016/j.ijheatmasstransfer.2018.05.021.

[66] Tariq, HA, Shoukat, AA, Anwar, M, Israr, A, Ali, HM. Water cooled micro-hole cellular structure as a heat dissipation media: an experimental and numerical study. Journal of Thermal Science 2018; 1: 1-13. https://doi.org/10.2298/TSCI180219184T.

[67] Khan, MS, Abid, M, Ali, HM, Amber, KP, Bashir, MA, Javed, S. Comparative performance assessment of solar dish assisted s-CO2 Brayton cycle using nanofluids. Appl Therm Eng 2019; 148: 295-306. https://doi.org/10.1016/j.applthermaleng.2018.11.021.

[68] Babar, H, Sajid, M, Ali, HM. Viscosity of hybrid nanofluids: a critical review. Journal of Thermal Science $2019 ; 15$.

[69] Sajid, MU, Ali, HM. Recent advances in application of nanofluids in heat transfer devices: a critical review. Renew Sust Energ Rev 2019; 103: 556-592. https://doi.org/10.1016/j.rser.2018.12.057.

[70] Mohanty, S, Parkash, O, Arora R. Analytical and comparative investigations on counter flow heat exchanger using computational fluid dynamics. Journal of Computational \& Applied Research in Mechanical Engineering 2019; 10.22061/JCARME.2019.4665.1564.

[71] Mohanty, S, Arora, R, Parkash, O. Performance prediction and comparative analysis for a designed, developed, and modeled counter flow heat exchanger using computational fluid dynamics. Computational Thermal Sciences: An International Journal 2019; 11(5):423-443. https://doi.org/ 10.1615/ComputThermalScien.2019028520. 
[72] Ahmed, SU, Arora, R, Parkash, O. Flow characteristics of multiphase glass beads-water slurry through horizontal pipeline using Computational Fluid Dynamics." International Journal of Automotive and Mechanical Engineering 2019; 16(2): 6605-6623.

[73] Ahmed, SU, Arora, R, Parkash, O. Prediction of Flow Parameters of Glass Beads-Water Slurry flow through Horizontal Pipeline using Computational Fluid Dynamics. Jordan Journal of Mechanical \& Industrial Engineering 2018; 12(3):197-213.

[74] Ahmed, S.U., Arora, R., Parkash, O. Numerical investigations on flow characteristics of sand-water slurry through horizontal pipeline using computational fluid dynamics. J. Therm. Eng 2020; 6(2):128-139.

[75] Parkash, O, Arora, R. Flow characterization of multi-phase particulate slurry in thermal power plants using computational fluid dynamics. J Therm Eng 2020; 6(1):187-203. https://doi.org/10.18186/thermal.672785.

[76] Arora, R, Arora, R. Thermodynamic optimization of an irreversible regenerated brayton heat engine using modified ecological criteria. J Therm Eng 2020; 6(1): 28-42. https://doi.org/10.18186/thermal.671079.

[77] Kaushik, SC, Kumar, R, Arora, R. Thermo-economic optimization and parametric study of an irreversible regenerative Brayton cycle. J Therm Eng 2016; 4(2):861-870. https://doi.org/10.18186/jte.70740.

[78] Dalkiliç, AS, Cebi, A, Celen, A. Numerical analyses on the prediction of nusselt numbers for upward and downward flows of water in a smooth pipe: effects of buoyancy and property variations. J Therm Eng 2019; 5(3): 166-180. https://doi.org/10.18186/thermal.540367.

[79] Anil, S, Dizman, T, Celen, A, Bilge, D, Dalkılıç, AS, Wongwises, S. CFD analysis of smoke and temperature control system of an indoor parking lot with jet fans. J Therm Eng 2015; 1(2): 116-130. https://doi.org/10.18186/jte.02276. 